\title{
Letters
}

Website: www.bmj.com

Email: letters@bmj.com

\section{Racism in psychiatry necessitates reappraisal of general procedures and Eurocentric theories}

EdITOR-We agree with the comment in Editor's Choice (in issue of 6 March) that the effects of the Stephen Lawrence case and the inquiry into it will be far reaching and that no public institution will be exempt. We doubt, though, that the soul searching that has followed the publication of the inquiry report will result in corrective action against institutional racism in the NHS. McKenzie's editorial is an indication of this ${ }^{1}$ : although he marshals the evidence to argue that institutional racism is very much part of the structure, procedures, and culture in the NHS, he offers few political and professional strategies to challenge discriminatory practices in the health services.

As McKenzie says, allegations of racial discrimination are not new in the NHS. But he has ignored the most glaring example of racial inequality in service provision in the NHS-that in psychiatry. It is often ignored in debates such as this because any attempt to deal with racism would necessitate a reappraisal of not only the general procedures of psychiatry but also the Eurocentric bias of our theories and a commitment to change the professional culture that is based on pathologising differences.

Psychiatry comes closest to the police among medical specialties in pursuing practices and procedures that explicitly discriminate against minority ethnic groups in the United Kingdom. The disproportionate numbers of black people in psychiatric detention, ${ }^{2}$ the overdiagnosis of schizophrenia in black people, the exclusion of black people from the "softer end" of psychiatric practice because they are deemed psychologically unsuitable, ${ }^{3}$ the alienation of black patients from mainstream psychiatric services, ${ }^{4}$ the general lack of trust and extreme scepticism about psychiatric practice that is evident in minority communities, and the professional preoccupation with theories of ethnic vulnerability or inferiority, which continue to echo the sentiments of 19th century race science, ${ }^{5}$ all confirm the similarities between policing the black communities and controlling their minds.

Unlike in other branches of medicine, the racial bias in treatment and outcome that is evident in psychiatry cannot be understood fully by an examination of procedures, practice, or policy governing service delivery. The theories and assumptions of psychiatry are problematic when they are applied to people who are socially excluded or culturally marginalised. Black communities in the United Kingdom will continue to bear the brunt of such a professional bias as long as the coordinates of psychiatric practice remain culturally fixed.

Obviously, sufficient challenge to institutional racism must include more than exhortations to examine our practice and change our attitudes. In psychiatry, any attempt to address this issue must incorporate a reappraisal of the purpose and function of professional practices and an alignment of critical professional voices with the larger struggle against racism. The home secretary's commitment to extend the Race Relations Act to the NHS is welcome; a useful start would be to set up a national inquiry into race and mental health.

S P Sashidharan Professor of community psychiatry Errol Francis Director, Frantz Fanon Centre for Mental Health

Northern Birmingham Mental Health (NHS) Trust, Academic Unit, Birmingham B23 6AL

1 McKenzie K. Something borrowed from the blues? BMJ 1999:318:616-7. (6 March)

2 Moodley P, Thornicroft G. Ethnic groups and compulsory Moodley P, Thornicroft G. Ethnic groups
detention. Med Sci Law 1988;28:324-8.

3 Fetnando S. Mental health, race and culture. London: MIND, 1991

4 McGovern D, Hemmings P. A follow up of second generation Afro-Caribbeans and white British with a first admission diagnosis of schizophrenia: attitudes to mental illness and psychiatric services of patients and relatives. $S o c S c$ Med 1994;38:117-27.

5 Sashidharan SP. Afro-Caribbeans and schizophrenia: the ethnic vulnerability hypothesis re-examined. Int Rev Psychiatry 1993;5:129-44

\section{Low vitamin D concentrations found in study of Asian children was not function of analytical method}

EDITOR-I would like to respond to the two letters ${ }^{1}$ commenting on the short report that Thomas and I wrote on vitamin D concentrations in Asian children. ${ }^{2}$ The diagnosis of rickets in a white infant associated with the use of a potent sunscreen that Zlotkin reports is interesting. The author quotes a study linking use of sunscreen with suppression of synthesis of vitamin $\mathrm{D}_{3}$, but a more recent study found no association between use of sunscreen and vitamin D metabolism. ${ }^{3}$

We did not collect data on the use of sunscreen, although perhaps this should be considered for future studies on vitamin D. For both our Asian study and the national diet and nutritional survey, ${ }^{4}$ serum 25-hydroxycholecalciferol concentration was assayed with the same kit (which uses an equilibrium radioimmunoassay procedure), although there were some minor methodological differences between the two studies. To see whether these differences might in part explain the difference in values seen in the two studies a number of samples were analysed both in the Leicester laboratory that analysed the samples for our study and in the Dunn laboratory in Cambridge, which analysed samples for the national study.

The two sets of values correlated well, and although the values from the Cambridge laboratory were slightly higher (mean difference $1.59 \mathrm{nmol} / 1$ ), the difference did not reach significance. The suggestion that the low concentrations found in our Asian study may be a function of the analytical method is therefore not substantiated.

\section{Margaret Lawson Senior lecturer in paediatric} nutrition

Childhood Nutrition Research Centre, Institute of Child Health, London WC1N 1EH

1 Correspondence. Vitamin D concentrations in Asian children living in England. BMJ 1999;318:1417. (22 May.) 2 Lawson MS, Thomas M. Vitamin D concentrations in Asian children aged 2 years living in England: population survey. BMJ 1999;318:28.

3 Farrerons J, Barnadas M, Rodriguez J, Renau A, Yoldi B, Lopez-Navidad A, et al. Clinically prescribed sunscreen does not decrease serum vitamin D concentration sufficiently either to induce changes in parathyroid function or in metabolic markers. Br J Dermatol 1998;139:422.

4 Gregory JR, Collins DL, Davies PSW, Hughes JM, Clarke PC. National diet and nutritional survey: children ared 1 15-4.5 years. London: HMSO, 1995.

\section{Recognition of depression and anxiety in primary care}

General practitioners in study seemed to agree with commentary writer

EDITOR-Kessler et al assessed the ability of general practitioners to diagnose depression and anxiety as defined by the general health questionnaire (GHQ-12). ${ }^{1}$ Unfortunately, they have miscalculated their results; from their data, the general practitioners had a sensitivity of $36 \%$ and a specificity of $91 \%$.

These figures suggest that the participating general practitioners-at least in their day to day practice-shared Heath's opinion in her commentary. ${ }^{1}$ Most patients with a score $>3$ on the general health questionnaire do not have a diagnosable psychiatric condition.

Allan House Senior lecturer in psychiatry

Division of Psychiatry and Behavioural Sciences in Relation to Medicine, School of Medicine,

University of Leeds, Leeds LS2 9LT

1 Kessler D, Lloyd K, Lewis G, Gray DP. Cross sectional study of symptom attribution and recognition of depression and anxiety in primary care [with commentary by I Heath]. anxiety in primary care with comm.
BMJ 1999;318:436-40. (13 February.) 


\section{Authors' reply}

EDITOR-Our paper had a hostile commentary from Heath. She ignored the substance of what we were saying about the importance of patients' attributional styles and criticised the use of the general health questionnaire ${ }^{1}$ as a screening instrument for depression and anxiety in general practice. Johnstone and Talbot have little to add to Heath's criticisms. ${ }^{2}$ Like her, they ignore the main body of the article. They point out that the general health questionnaire is "able to screen only for psychological disorder in general," a fact which we acknowledge in the text of our article. We used the general health questionnaire to define cases of psychological disorder, and since the research evidence shows that most such disorders in primary care are affective in nature, we asked the general practitioners to identify cases of anxiety or depression.

House is right to point out that the general practitioners' overall sensitivity in identifying general health questionnaire cases was $36 \%$ and their specificity $91 \%$, not $57 \%$ and $80 \%$ as published, and we apologise for the error. Despite this, our evidence is that general practitioners tend to agree with the general health questionnaire. Of the 71 patients diagnosed by their general practitioners as depressed or anxious, all but 14 were cases by the general health questionnaire, and seven of them had a recent diagnosis of depression and were recovering while receiving treatment. Furthermore, the higher the patient's score on the general health questionnaire the more likely was the general practitioner to make a psychological diagnosis.

But what about the cases where the general practitioner and the questionnaire did not agree? We found that patients' attributional style had a significant effect on diagnostic outcome irrespective of score on the general health questionnaire. Distressed patients who thought psychologically about their symptoms were often identified as depressed; those who normalised or minimised their symptoms were rarely thought of as having a psychological disorder.

Herran et al lend support to our thesis. ${ }^{3}$ Like them, we believe that the diagnosis and treatment of psychiatric illness by general practitioners is influenced by patients' attributional styles. Like Johnstone and Talbot, ${ }^{2}$ we believe that "improvement in detection is likely to come about from research into closer liaison of general practitioners and their psychiatric colleagues"-witness our own collaboration. But we would also emphasise the importance of a better understanding of how patients think about their illnesses.

David Kessler Honorary research fellow Denis Pereira Gray Professor of general practice Institute of General Practice, Postgraduate Medical School, University of Exeter, Exeter EX2 5DW

Keith Lloyd Senior lecturer

Department of Mental Health, University of Exeter, Wonford House Hospital, Exeter EX2 5AF

Glyn Lewis Professor of community and

epidemiological psychiatry

Division of Psychological Medicine, University of

Wales College of Medicine, Cardiff CF4 4XN
1 Goldberg D, Williams P. A user's guide to the general health questiomnaire. Windsor: NEFR Nelson, 1991.

Johnstone T, Talbot P. Recognition of depression and anx ety in primary care. BMJ 1999;318:1558-9. (5 June.)

3 Herran A, Vazquez-Barquero JL, Dunn G. Recognition of depression and anxiety in primary care. BMJ 1999;318 1558. (5 June.)

\section{Why heart disease mortality is low in France}

\section{Miscoding may explain Japan's low} mortality from coronary heart disease

EDITOR-We agree with Law and Wald that one must consider the cohort effect-the time lag-in investigating the association of levels of risk factors with mortality from coronary heart disease. ${ }^{1}$ Analysis of mortality from coronary heart disease in birth cohorts since the second world war is therefore important.

We evaluated mortality from coronary heart disease in the United States, Japan, South Korea, and other countries, as well as within the United States by state, for men aged 35-44. We found that the very low mortality from coronary heart disease in Japan (5.5/100 000, compared with 11.4/ 100000 in South Korea and 26.4/100 000 among American white men in 1992) might be an artefact.

A substantial proportion of mortality from coronary heart disease among men aged 35-44 may be miscoded as heart failure (ICD-9, code 428) because in Japan more than $60 \%$ of mortality from diseases of the heart (codes 390-429) was coded as heart failure. This proportion is usually very low in this age group- $1 \%$ among American white men. If half the mortality from heart disease was due to coronary heart disease in Japan there would be only a twofold difference in mortality from coronary heart disease between the United States and Japan: 26.4/100 000 among American white men versus 13.5/100 000 among Japanese men in 1992.

In some states in the United States we found that mortality from coronary heart disease among white men aged 35-44 is similar to that in France $(14.7 / 100000)$ : $13.8 / 100000$ in Washington, $14.7 / 100000$ in Connecticut, 15.4/100 000 in Kansas, $16.4 / 100000$ in Colorado, and 17.1/ 100000 in California. The low rates in these states are not due to heavy alcohol consumption compared with that in other states; rather, they are strongly related to educational attainments of the population and the prevalence of cigarette smoking and perhaps other risk factors.

Studies of recent birth cohorts by country provide better evaluation of causes of death and measurements of atherosclerosis. Focusing on smaller geographic areas as opposed to whole countries may improve understanding of geographic variation in mortality from coronary heart disease. Alcohol may be an important attribute for a lower rate of coronary heart disease in France but is not necessarily the only key factor.
Atherosclerosis has a long incubation period. Diet measured 30 years before reported death may better predict the extent of atherosclerosis and mortality from coronary heart disease.

Akira Sekikawa Fellow

Lewis H Kuller Professor

Department of Epidemiology, Graduate School of Public Health, University of Pittsburgh, Pittsburgh, PA, 15261, USA akira+@pitt.edu

1 Law M, Wald N. Why heart disease mortality is low in France: the time lag explanation [with commentaries by M Stampfer and E Rimm, D J P Barker, and J P Mackenbach and A E Kunst and authors' response]. BMJ 1999;318:1471-80. (29 May.)

\section{Authors' hypothesis is wrong}

EDITOR-The idea of a time lag between increases in consumption of saturated fatty acids and an increase in mortality from coronary heart disease, presented by Law and Wald, ${ }^{1}$ was shown to be wrong many years ago.

A host of confounding variables may explain an association between a population's consumption of saturated fatty acids at a certain time and mortality from heart disease. ${ }^{2}$ Secular trends are more reliable. If the amount of saturated fatty acids in the diet is important, changes in their consumption should eventually be followed by similar changes in mortality from heart disease even if the initial correlation is false.

In a recent review I presented the results of the four most comprehensive studies of secular trends, including 103 time periods in 36 countries. $^{3}$ In 30 time periods consumption of saturated fatty acids had increased, as had mortality from coronary heart disease. But in 33 periods in which consumption had increased, mortality from coronary heart disease had remained unchanged in 10 and had decreased in 23.

Of particular interest for the Law-Wald hypothesis is one of the studies, in which the changes in mortality from coronary heart disease were correlated with the changes in consumption of saturated fatty acids over 24 years. In that study an increase in mortality from coronary heart disease had followed an increase in consumption of saturated fatty acids in seven countries. In 11 countries, however, where consumption had increased by between $15 \%$ and $190 \%$ (mean $54 \%$ ), mortality from coronary heart disease had been unchanged in three countries and had decreased by between $6 \%$ and $27 \%$ (mean 15\%) in eight.

This should not be a surprise because the combined results from eight ecological, 41 cross sectional, 25 cohort, and six case-control studies as well as a metaanalysis of nine controlled randomised trials also contradict the suggestion that consumption of dietary saturated fatty acids has any influence on atherosclerosis or coronary heart disease. ${ }^{3}$ There is no French paradox either. Anyone who plots the data from the MONICA (monitoring trends and determinants in cardiovascular disease) study will find that the French data just happen to be situated at the extreme corner of a scatter 
diagram that includes most combinations of consumption of saturated fatty acids or serum cholesterol and mortality from coronary heart disease.

Uffe Ravnskov Independent researcher Råbygatan 2, Lund, Sweden

uffe.ravnskov@swipnet.se

1 Law M, Wald N. Why heart disease mortality is low in France: the time lag explanation [with commentaries by M Stampfer and E Rimm, D J P Barker, and J P Mackenbach and A E Kunst and authors' response]. BM 1999;318:1471-80. (29 May.)

2 Yerushalmy J, Hilleboe HE. Fat in the diet and mortality from heart disease. A methodologic note. NY State J Med 1957;57:2343-54

3 Ravnskov U. The questionable role of saturated and polyunsaturated fatty acids in cardiovascular disease. J Clin Epidemiol 1998;51:443-60.

\section{Pressures of acute obstetrics on consultants}

\section{Consultants are stretched to their limits}

EDITOR-I work as one of four consultant obstetricians in an average district general hospital. We were all appointed about 10 years ago and are all aged over 50. A recent guideline from our royal college advised us that if we were performing fewer than 20 amniocenteses a year, we should ask ourselves if we should be doing any at all.

I have recently used the department's computer system to confirm that, for the four of us, our combined hands-on consultant experience of acute obstetrics over the past three years (out of about 9000 deliveries, around 750 of them assisted) has been: spontaneous deliveries, 6; Ventouse deliveries, 0 ; low forceps deliveries, 12; other forceps deliveries, 7 ; vaginal breech deliveries, 2; emergency caesarean sections, 26.

I therefore ask: Is it safe for us to be allocated one labour ward session per consultant per week "teaching" the on-call registrar? When we are already stretched to our limits with multiple other responsibilities, what training should we be required to undertake to allow us to continue to be responsible for the labour ward? Is it safe for us to continue to provide any acute obstetric cover at all? What updating training programme should we regularly attend? While we are urgently being retrained in acute obstetrics, who will provide consultant cover for the labour ward?

Consultant obstetrician and gynaecologist

** The BMJ knows the author's name but has decided to respect the request for anonymity.EDITOR

\section{Reply from Royal College of} Obstetricians and Gynaecologists

EDITOR-Presumably the anonymous correspondent, like other consultants working in district general hospitals, takes part in an on-call rota. This involves taking decisions on the management of labour and attending emergencies that may be life threatening. It is therefore essential for this doctor to accept responsibility for keeping up to date.
The General Medical Council states that individual doctors are responsible for maintaining the standards of their own practice and that "in providing care you must recognise and work within the limits of your professional competence."1 If this doctor no longer feels competent to provide obstetric cover he or she should discuss the problem urgently with the medical director or chief executive of his or her trust.

There are now several updating courses on obstetric emergencies-for example, one is run regularly at the North Staffordshire Hospitals Trust. The problem of consultants becoming deskilled in routine obstetrics is addressed by the recent recommendations from this college and the Royal College of Midwives that in an average district general hospital a consultant should be present on the labour ward, without other commitments, for 40 hours a week. ${ }^{2}$

We have urged all trusts to implement this recommendation as soon as possible. The college recognises that because consultants are already stretched to their limits this will mean new consultant posts, and I wrote in April to all trust chief executives in the United Kingdom to point this out. Our recommendation needs local support from consultants. The author of this letter will help his or her future patients by addressing this problem openly, not anonymously.

Robert W Shaw President

Royal College of Obstetricians and Gynaecologists, London NW1 4RG

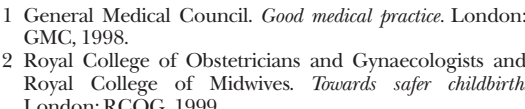

1 General Medical Council. Good medical practice. London: GMC, 1998.

2 Royal College of Obstetricians and Gynaecologists and Royal College of Midwives. Towards safer childbirth Rondon: College of

\section{At least 35\% more orthopaedic surgeons are needed to ensure consultant based service}

EDITOR-Collins's editorial on surgical training and service highlights major concerns for the adequacy of training and supervision of surgeons in the new "Calman environment." ${ }^{1}$ His findings in general surgery echo those I reported recently from a survey of supervision levels in orthopaedic surgery."

In a questionnaire survey of fellows of the British Orthopaedic Association (comprising virtually all consultant orthopaedic surgeons in the United Kingdom) 849 $(69 \%)$ of 1230 fellows responded. The survey indicated the widespread practice of delegating workload to unsupervised junior staff. In $284(37.2 \%)$ of 763 surgeons' practices the situation could-at least theoretically-arise that patients are assessed preoperatively, operated on, and followed up without being seen by the consultant. This study took account only of elective work: I strongly suspect that the figures for the supervision of trauma would be even more disquieting.

The figures suggest that we need at least $35 \%$ more orthopaedic surgeons at once, simply to ensure a true consultant based service with time for adequate supervision of trainees, and this does not take account of any increase in numbers of patients or clinical workload.

John Lourie Consultant orthopaedic surgeon Department of Orthopaedic Surgery, Milton Keynes Hospital, Milton Keynes MK6 5LD

\section{Collins C. Surgical training, supervision, and service. BMJ 1999;318:682-3. (13 March.) \\ 2 Lourie J. Delegation of orthopaedic workload. Ann R Coll Surg Engl 1998;80(suppl):260-4.}

\section{Author defends meta-analysis that was criticised}

EdTOR-In their continuous and compelling search for faults in published research, Davey Smith and Egger have written a letter about meta-analysis that is inaccurate. ${ }^{1}$ In their reference to a meta-analysis of observational data that I and colleagues did $^{2}$ and the reanalysis that followed ${ }^{3}$ the authors commit two sins. The first is to misquote the original paper and the second, more important, is not to cross check the facts.

They say that "Cappuccio et al argued that this [their finding] could be expected." Nowhere in the original manuscript is there such a statement. This interpretation has been carefully construed from the paragraph discussing potential sources of heterogeneity, where we conclude that "it seems more likely that other characteristics, either not measured or not considered in the analysis, may explain the differences across studies." "Correcting the metaanalysis for this error (and several other mistakes)," Davey Smith and Egger then plot Birkett's estimates in their figure. However, they have ignored our response to Birkett's article, where we clearly challenged some of Birkett's calculations. ${ }^{4}$

Davey Smith and Egger seem to misinterpret human error as misleading meta-analysis. While the inaccuracies discussed (and in part acknowledged ${ }^{4}$ ) have led to minor changes in the overall estimate of effect (the relevance of which is minimal and openly discussed in view of the results of controlled trials ${ }^{5}$ ), by the use of misquotes and inaccuracies their letter will mislead those readers who are unlikely to read the original publications.

Francesco $\mathbf{P}$ Cappuccio Reader in preventive cardiovascular medicine

St George's Hospital Medical School, London SW17 0RE

f.cappuccio@sghms.ac.uk

1 Davey Smith G, Egger M. Meta-analyses of observational data should be done with due care. BMJ 1999;318:56. (2 January.)

2 Cappuccio FP, Elliott P, Allender PS, Pryer J, Follman DA, Cutler JA. Epidemiologic association between dietary calcium intake and blood pressure: a meta-analysis of published data. Am J Epidemiol 1995;142:935-45.

3 Birkett NJ. Comments on a meta-analysis of the relation between dietary calcium intake and blood pressure. $\mathrm{Am} \mathrm{J}$ Epidemiol 1998;148:223-8.

4 Cappuccio FP, Elliott P, Follmann D, Cutler JA. Authors' response to "Comments on a meta-analysis of the relation between dietary calcium intake and blood pressure" $A m J$ Epidemiol 1998:148:232-3.

5 Cappuccio FP. The "calcium antihypertension theory." Am J Hypertens 1999;12:93-5. 


\section{Management of preterm labour}

\section{Nifedipine in management of preterm labour is safe}

EDITOR-Steer and Flint stated in their article in the $\mathrm{ABC}$ of labour care that the use of sympathomimetics is generally the safest choice for the mother and the fetus and that calcium channel blockers cause significant hypotension. ${ }^{1}$ We disagree with this.

In studies in pregnant women nifedipine has minimal cardiovascular and metabolic effects during clinical use, in contrast with $\beta_{2}$ sympathomimetics such as ritodrine. ${ }^{2}$ Nifedipine in the management of preterm labour is associated with significantly fewer maternal side effects than ritodrine. ${ }^{3}$ In our study we never had to stop treatment in the nifedipine group because of severe maternal side effects, whereas we did in 12 patients in the ritodrine group. ${ }^{3}$ No patients in the nifedipine group had hypotension while receiving treatment. Two patients in the ritodrine group had such changes on the electrocardiogram that the drug had to be stopped; this did not occur in any of the patients in the nifedipine group.

In our opinion, nifedipine is a safe and effective firstline tocolytic agent.

D N M Papatsonis Resident

Hoog.pap@wxs.nl

H P van Geijn Professor of obstetrics and gynaecology Division of Maternal-Fetal Medicine, Department of Obstetrics and Gynaecology, Free University Hospital, Amsterdam, Netherlands

G A Dekker Professor of obstetrics and gynaecology Department of Obstetrics and Gynaecology, University of Adelaide (NWAHS), Adelaide, Australia

1 Steer P, Flint C. ABC of labour care: Preterm labour and premature rupture of membranes. BMJ 1999;318:1059-62. (17 April.)

2 Ferguson JE II, Dyson DC, Holbrook RHJ, Schutz T, Stevenson DK. Cardiovascular and metabolic effects assoStevenson DK. Cardiovascular and metabolic effects asso-
ciated with nifedipine and ritodrine tocolysis. Am J Obstet ciated with nifedipine and
Gynecol 1989;161:788-95.

3 Papatsonis DN, Van Geijn HP, Ader HJ, Lange FM, Bleker OP, Dekker GA. Nifedipine and ritodrine in the OP, Dekker GA. Nifedipine and ritodrine in the management of preterm labor: a
trial. Obstet Gynecol 1997;90:230-4.

4 Koks CAM, Brölman HAM, de Kleine MJK, Manger PA. A randomized comparison of nifedipine and ritodrine for suppression of preterm labor. Eur J Obstet Gynecol Reprod Biol 1998;77:171-6.

\section{Author's reply}

EDITOR-Papatsonis et al's letter gives me the opportunity to expand on our comments about tocolytics. I am also grateful to Dr Joel Ray, who has corresponded with me on this topic via the $B M$ Js website and sent me a copy of his useful meta-analysis, published in 1998.

In his introduction Ray comments that " $\beta$ agonists continue to remain the recommended first choice for tocolysis in labour." His review of seven randomised trials of acceptable quality comparing nifedipine with $\beta$ agonists (culled from 1555 relevant articles) showed that the confidence interval for tocolysis lasting 48 hours overlaps zero (odds ratio 1.34 (95\% confidence interval 0.83 to 2.15)). Of the seven trials, four favoured nifedipine but three favoured the $\beta$ agonist. Ray referred to the trial by
Papatsonis et al but did not include it in the analysis because "the authors' exclusive use of an on-treatment analysis leaves some uncertainty about the external validity of their data."

The meta-analysis did show that the incidence of maternal side effects was significantly lower with nifedipine (odds ratio $0.26(0.16$ to 0.43$))$. While nifedipine seems to be better tolerated by the mother, however, doubts about its safety for the fetus have been raised by reports of fetal hypoxia and acidosis in sheep infused with nifedipine. ${ }^{2}$ In humans sublingual nifedipine can cause severe maternal hypotension with accompanying fetal distress. ${ }^{3}$ Calls have been made for the use of sublingual nifedipine capsules to be abandoned because of reports of serious adverse effects such as cerebrovascular ischaemia, stroke, severe hypotension, acute myocardial infarction, conduction disturbances, fetal distress, and death. ${ }^{4}$ Hypotension may be a particular risk if magnesium sulphate is also being used, $^{5}$ as it often is in hypertensive pregnancy.

Perinatal outcome was not addressed in Ray's analysis, and he concluded that "a large randomised clinical trial is needed to compare the neonatal outcomes of the therapies." I agree.

Philip Steer Professor

Imperial College School of Medicine, Chelsea and Westminster Hospital, London SW10 9NH p.steer@ic.ac.uk

1 Ray JG. Meta-analysis of Nifedipine versus betasympathomimetic agents for tocolysis during preterm labour. J Soc Obstet Gynaecol Can 1998;20:259-69.

2 Blea CW, Barnard JM, Magness RR, Phernetton TM, Hendricks SK. Effect of nifedipine on fetal and matern hemodynamics and blood gases in the pregnant ewe $A m J$ Obstet Gynecol 1997;176:929-30.

d fetal distress following ins followin (o a patient wit severe pregnancy induced hypertension at 33 weeks. $\mathrm{Br}$

4 Grossman E, Messerli FH, Grodzicki T, Kowey P. Should moratorium be placed on sublingual nifedipine capsule given for hypertensive emergencies and pseudoemergencies? JAMA 1996;276:1328-3

5 Waisman GD, Mayorga LM, Camera MI, Vignolo CA, Martinotti A. Magnesium plus nifedipine: potentiation of hypotensive effect in preeclampsia? Am J Obstet Gynecol $1988 ; 159: 308-9$.

\section{Many reports of RCTs give insufficient data for Cochrane reviewers}

Editor-We endorse the call in Editor's choice in the issue of 31 October for improvement in the performance of clinical trials. As part of the Cochrane Airways Group we are carrying out a systematic review of trials on the use of $\beta$ agonists in asthma. In many of our selected publications we have found it difficult to tell whether allocation of treatment was adequately concealed.

The reviews undertaken for the Cochrane Collaboration aim to include only those studies in which selection bias has been minimised. For our review of regular short acting $\beta$ agonists versus use as required we identified 30 studies that were randomised controlled trials. Only five gave sufficient information for us to say with certainty that there had been adequate concealment. Many of the others, however, had been carried out in major centres of high quality research where they almost certainly did use accepted randomisation methods, details being held by a third party. Editors of journals should insist that, rather than giving the general statement that the design was randomised and double blind, reports should give a short description of the randomisation method used.

A second difficulty we have faced has been authors' tendency not to publish their results in a form that is directly usable by reviewers. In our series we have been able to extract fully all the data on reported outcomes in only six of the 30 papers; 15 yielded none, because what was presented was derivative (such as the change from baseline) or merely the $\mathrm{P}$ value for some statistical comparison. It would seem sensible for editors to ask for the basic data to be published, made available on request, or made available on the internet. When we or other readers write and request the basic data later they can be difficult to access or the people who were originally responsible for them may have moved. The lack of response to such requests has been a problem for some Cochrane reviewers.

Although perfection may be impossible, editors of journals could make a positive impact by insisting on more appropriate criteria for the presentation or availability of data, with a specific view to future systematic reviews.

E Haydn Walters Professor and director Department of Respiratory Medicine, The Alfred and Monash Medical School, Prahran, Melbourne, Victoria 3181, Australia

Haydn.Walters@med.monash.edu.au

J A E Walters Lecturer

Department of Respiratory Medicine, Monash

Medical School, Prahran, Melbourne, Victoria 3181

Julia.Walters@med.monash.edu.au

\section{Electronic bibliographic tools} for incorporating social science research into health care must be improved

EDitoR-Will the new database that the National Institutes of Health is proposing be dominated by clinical and laboratory science and give short shrift to social science? ${ }^{1}$ Electronic bibliographic tools for social science research into health care remain underdeveloped and inadequate. This problem needs to be addressed by the healthcare community if healthcare practice is to be informed by systematic evidence from the social sciences.

Funding bodies worldwide are paying an increasing amount of money to social scientists (often economists) to generate useful knowledge about the organisation and delivery of health care and the economic, social, and political implications of medical drugs, devices, and procedures. To generate useful knowledge on a particular healthcare 
topic, a systematic review of the relevant literature needs to be done. Yet electronic bibliographic tools for the social sciences are not up to this job.

In our experience, well conducted electronic searches with social science keywords are more time consuming, less precise, and less sensitive than searches performed with clinical and laboratory science keywords. One problem is that social science keywords are not standardised and the accuracy of key terms (such as "cost effectiveness analysis") is not enforced. Another problem is that health related social sciences journals are spread out in many different overlapping databases. A third problem is that a high proportion of relevant social science material remains "grey" literature, published in books and reports that are not covered by standard electronic databases that are easy to access. The root cause of all three problems is that social scientists are forced to use electronic databases of healthcare knowledge that have been designed for clinicians and laboratory scientists, not social scientists.

The consequence of this is that most social scientists in health care continue to use old fashioned methods of literature review; they have been reluctant to invest in the skills necessary to use modern, formal methods of systematic review. This distorts the social science evidence base because informal literature review methods are susceptible to bias towards references that happen to be suggested by colleagues; at worst they can allow narrow schools of thought to dominate the social science advice given to practitioners.

We have no concrete proposals to deal with this problem and are merely saying that debate is needed. It will then be up to journal editors, database providers, and research funding bodies to find ways of cooperating to improve national and international electronic database tools for social science research in health care.

Richard Cookson Research officer

r.cookson@lse.ac.uk

Luke Archard Research officer

David McDaid Research officer

LSE Health, London School of Economics,

London WC2A $2 \mathrm{AE}$

Delamothe T. NIH outlines strategy for electronic database. BMJ 1999;318:165. (1 May.)

\section{Royal College of Surgeons of Edinburgh gives consultant fellows feedback on their training activity}

EDITOR-Aitken et al have brought to our attention the important topic of training in large bowel cancer surgery. ${ }^{1}$ In 1992 the Royal College of Surgeons of Edinburgh began an audit of surgical training, providing consultant fellows with feedback on their training activity. Consultants from all specialties were invited to take part, and an increasing number have done so since the audit was started.
Percentages of cases in which a trainee was supervised at operation by assisting consultant or senior registrar (and total numbers of operations)

\begin{tabular}{|c|c|c|c|}
\hline \multirow[b]{2}{*}{ Procedure } & \multicolumn{3}{|c|}{ Year* } \\
\hline & 1993 & 1994 & 1996 \\
\hline \multicolumn{4}{|l|}{ General surgery } \\
\hline Colonic resection & $11(321)$ & $21(554)$ & $22(542)$ \\
\hline Cholecystectomy & $17(534)$ & $21(968)$ & $24(567)$ \\
\hline \multicolumn{4}{|l|}{ Gynaecology } \\
\hline $\begin{array}{c}\text { Bladder neck } \\
\text { suspension }\end{array}$ & $9(33)$ & NA & NA \\
\hline $\begin{array}{l}\text { Abdominal } \\
\text { hysterectomy }\end{array}$ & NA & $28(255)$ & $30(252)$ \\
\hline Vaginal hysterectomy & NA & $16(104)$ & $19(150)$ \\
\hline
\end{tabular}

Ophthalmology

\begin{tabular}{lrrr}
\hline Cataract & NA & $3(1681)$ & $4(2025)$ \\
\hline Squint & NA & $13(210)$ & $10(177)$ \\
\hline Trabeculectomy & NA & $3(204)$ & $1(138)$ \\
\hline
\end{tabular}

Orthopaedics

\begin{tabular}{llll}
\hline Total hip replacement & NA & NA & $1(137)$ \\
\hline Arthroscopic surgery & NA & NA & $3(205)$ \\
\hline
\end{tabular}

\section{Vascular}

\begin{tabular}{lrcc}
\hline Femoropopliteal bypass & NA & $8(222)$ & $9(169)$ \\
\hline Aortic aneurysm & NA & $17(183)$ & $9(215)$ \\
\hline Carotid endarterectomy & NA & NA & $14(102)$
\end{tabular}

NA=not available.

*Data for 1993 and 1994, when complete, refer to same surgeons; data for 1996 were obtained in a similar but not identical cohort.

In colorectal surgery, in 1993 a total of $11 \%$ of resections (for malignant and non-malignant disease) were undertaken by trainees with the consultant assisting; this figure rose to $21 \%$ by the next year, although no further improvement was seen in the 1996 data (table). Consultants were present at $60 \%$ of colonic resections in $1993,70 \%$ in 1994, and $73 \%$ in 1996. Figures for cholecystectomy were similar. In urology, vascular surgery, ophthalmology, and orthopaedics our data suggest that the figures for trainees operating under supervision might be even less satisfactory.

Hospitals with training posts should be obliged to collect, on a routine basis, reliable data that allow consultants to have information on their training role. Colleges should consider setting targets to ensure that surgical training is more focused.

D R Harper Chairman, advisory committee on audit Royal College of Surgeons of Edinburgh, Edinburgh EH8 9DW

DouglasHarper1@compuserve.com

1 Aitken RJ, Thompson MR, Smith JAE, Radcliffe AG, Stamatakis JD, Steele RJC. Training in large bowel cance surgery: observations from three prospective regiona United Kingdom audits. BMJ 1999;3 18:702-3. (13 March.)

\section{Community study of infectious intestinal disease in England}

\section{Study underestimated morbidity due to specific pathogens}

EDITOR-Wheeler et al's paper estimates the burden of symptomatic infectious intestinal disease in the United Kingdom. ${ }^{1}$ One aspect of their findings was the high proportion $(55 \%)$ of community episodes in which no pathogen was identified. I would suggest that this study severely underestimates the prevalence of certain intestinal pathogens. For example, the authors calculate the incidence of cryptosporidium infection in their community study to be only $0.81(95 \%$ confidence interval 0.26 to 2.5$)$ per 1000 person years.

Another approach to determining the incidence of an infectious disease is to determine the prevalence of antibodies in the community and then calculate the annual attack rate required to give that degree of antibody positivity. If an individual is assumed to remain antibody positive for life after an infection then this attack rate is given by a simple formula: cases $/ 100$ person years $=\%$ seropositive/ average life expectancy.

Few studies of cryptosporidium antibodies have been carried out in the United Kingdom, but McLauchlin et al reported prevalences of $21 \%$ and $49 \%$ in two areas. ${ }^{2}$ In Oklahoma in the United States rates in adolescents were up to $58 \%{ }^{3}$ Given that life expectancy in the United Kingdom is about 76 years, this would give an estimated attack rate of up to 6.58/1000 person years (for $50 \%$ positivity), some eight times higher than that suggested by Wheeler et al. This figure itself is probably an underestimate given the observation that infection in human volunteers offers little protection against reinfection one year later. ${ }^{4}$ If individuals suffer repeated infection or if antibodies become undetectable after only a few years the real infection rate may be many times greater still.

The arguments that I have presented apply equally to other pathogens. We must be cautious about using data collected from this type of study in assessing the health and cost benefits of public health interventions aimed at single pathogens. A study of the seroepidemiology of various enteric pathogens is needed.

Paul R Hunter Consultant medical microbiologist Public Health Laboratory, Countess of Chester Health Park, Chester CH2 1UL

Paul.Hunter3@virgin.net

1 Wheeler JG, Sethi D, Cowden JM, Wall PG, Rodrigues LC Tomkins DS, et al. Study of infectious intestinal disease in England: rates in the community, presenting to general practice, and reporting to national surveillance. $B M J$ 1999;318:1046-50. (17 April.)

2 McLauchlin J, Casemore DP, Moran S, Patel S. The epidemiology of cryptosporidiosis: application of experimental sub-typing and antibody detection systems to the investigation of water-borne outbreaks. Folia Parasitol investigation

3 Kuhls T, Moiser DA, Crawford D, Griffs J. Seroprevalence of cryptosporidial antibodies during infancy, childhood of cryptosporidial antibodies during infan

4 Okhuysen PC, Chappell CL, Sterling CR, Jakubowski W, Okhuysen PC, Chappell CL, Sterling CR, Jakubowski W,
DuPont HL. Susceptibility and serologic response to DuPont HL. Susceptibility and serologic response to
healthy adults to reinfection with Cryptosporidium parvum. Infect Immun 1988;66:441-3.

\section{Authors' reply}

EDITOR-The proportion of community episodes in which no pathogen was identified was $63 \%$, rather than the $55 \%$ that Hunter inferred from table 1 in our paper. The discrepancy arises because of exclusions and stool samples not tested (points noted in the footnotes to table 1). 
We acknowledge that diagnostic techniques for many enteric pathogens lack sensitivity. ${ }^{1}$ Our method for detecting cryptosporidium oocysts is that recommended for screening stools for this pathogen. ${ }^{2}$ Although our study was the largest incidence study of infectious intestinal disease in the United Kingdom, its focus was broad for every pathogen sought. In the community component of the study only three cases of infection with Cryptosporidium parvum were detected, and we recognise that this makes our estimate of incidence fairly imprecise, with a corresponding wide confidence interval.

Seroepidemiological studies are important, but their use to determine disease incidence must be viewed with caution. Hunter does not differentiate between infection and disease. Our study also tested stools of healthy controls and found $0.1 \%$ to be positive for cryptosporidium. These may be asymptomatic infections or evidence of past infections.

Ingestion of oocysts in water does not lead automatically to disease, because of variable factors such as infective dose, strain specific pathogenicity, and host immunity. ${ }^{3}$ Techniques used in routine laboratory detection fail to discriminate between genotypes of crytosporidium; some seem to confer some host specificity for humans and farm animals. ${ }^{4}$ The relative pathogenicity of these genotypes and the balance between infection and disease is yet to be established.

The derivation of incidence from prevalence uses simplifying assumptions and ignores any age, period, and cohort effects on incidence. The sample's age composition affects the projected incidence, particularly if persistence of antibodies varies with age. Long lasting antibodies may also reflect infection rates in previous decades. Like cryptosporidium, Helicobacter pylori is largely acquired in childhood; high current rates of seropositivity in elderly people reflect poorer social conditions 50 years ago. ${ }^{5}$ In addition, systemic antibody levels may not accurately represent mucosal responses in the gastrointestinal tract.

We believe that the main reason for the difference in estimated incidence between our study and Hunter's figures is the wide geographical variation in rates of cryptosporidium infection. The attack rate that Hunter estimated was based on data from an area where a large outbreak had recently occurred, and a high seroprevalence would be expected. It is important that community studies to estimate national incidences are based on representative samples.

Jeremy $\mathbf{G}$ Wheeler Lecturer, infectious disease epidemiology

jerry.wheeler@lshtm.ac.uk

Laura C Rodrigues Senior lecturer, infectious disease epidemiology

Dinesh Sethi Lecturer, international public health

Infectious Disease Epidemiology Unit, Department of Infectious and Tropical Diseases, London School of Hygiene and Tropical Medicine, London WCIE 7HT
David S Tompkins Consultant medical microbiologist Leeds Public Health Laboratory, Leeds LS15 7TR

Michael J Hudson Principal microbiologist Centre for Applied Microbiology and Research, Porton Down, Salisbury, Wiltshire SP4 0JG

Paul J Roderick Senior lecturer in public health medicine

Southampton University, Southampton SO6 6YD

John M Cowden Consultant epidemiologist Scottish Centre for Infection and Environmental Health, Ruchill Hospital, Glasgow G20 9NB

Patrick G Wall Chief executive

Food Safety Authority of Ireland, Dublin 1, Republic of Ireland

1 Rosignol JF. Parasitic gut infections. Curr Opin Infect Dis 1998;11:557-600.

2 Casemore DP, Roberts C. Guidelines for screening for Cryptosporidium in stools. Report of a joint working roup. J Clin Pathol 1993:46:2-4.

3 Broup.J Clin Pathol 1993;46:2-4. Badenoch J (chairman). Second report of the group of experts

Patel S, Pedraza-Diaz S, McLauchlin J, Casemore DP

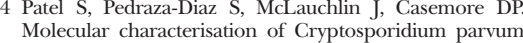
Molecular characterisation of Cryptosporidium parvum
from two large suspected waterborne outbreaks. Commun Dis Public Health 1998;1:231-3.

5 Banatvala N, Mayo K, Megraund F, Jennings R, Deeks JJ Feldman RA. The cohort effect and Helicobacter pylori. Infect Dis 1993;168:219-21.

\section{All parents should be given leaflet outlining full details of antenatal screening}

EDITOR-Price's unhappy experience of scanning during pregnancy is not uncommon. ${ }^{1}$ Many women are poorly informed about the role of screening tests in the first half of pregnancy. ${ }^{2}$ Health professionals often provide little and sometimes inaccurate information about these tests. ${ }^{3}$ Once an abnormality has been suspected or diagnosed many women report inadequacies in the information they receive or the way it is given. ${ }^{4}$ Guidelines for screening are discussed in a report from the Royal College of Obstetricians and Gynaecologists and Royal College of Paediatrics and Child Health. ${ }^{5}$

All pregnant women should receive a leaflet written in plain language describing all forms of antenatal screening, their advantages and limitations, together with possible risks to the unborn child and the freedom to accept or reject what is on offer It should include the three main reasons why ultrasound scanning is used in early pregnancy, as follows :

(1) You may just want to see your baby. This is practical any time after 12 weeks. If there is concern that you might have had a miscarriage because you had vaginal bleeding the presence of the heartbeat can be checked after 7 weeks.

(2) A doctor may suggest a scan when there is doubt about your baby's age. This may be because you are unsure of the time of your last menstrual period or when you conceived, or because the size of the womb does not seem to match up with how long you have been pregnant. The brief scan involves measuring the baby's head and possibly length. However, because the size of babies varies in mid-pregnancy, the age estimates are not precise.
(3) You can have a detailed scan of your baby to search for abnormalities at 18-20 weeks, when all the organs can be readily seen. The sonographer (the person doing the scan) looks at your baby's head, brain, spine, heart, lungs, kidneys, abdominal wall, and limbs. If the findings suggest that your baby may have an abnormality you will be referred for a further examination by a consultant radiologist. A consultant paediatrician will discuss with you and your partner what life would probably be like for a child with a predicted abnormality.

If you consider abortion unacceptable you may choose to have a scan later in pregnancy. If an abnormality was found then you would be cared for jointly by an obstetrician and a paediatrician, who would help to prepare for your child's future needs.

W M O Moore Consultant obstetrician

4 Lyme Grove, Altrincham WA14 2AD

\section{Price BE. Scanning during pregnancy is often for doctors benefit rather than parents'. BMJ 1999;318:1489. (29 Mav.) 2 Smith DK, Shaw RW, Marteau TM. Informed consent to undergo serum screening for Down's syndrome: the gap between policy and practice. BMJ 1994:309:776. \\ 3 Marteau TM, Slack J, Shaw RW. Presenting a routine screening test in antenatal care: practice observed. Public Health1992;106:131-41. \\ 4 Statham H, Green J. Serum screening for Down's syndrome: some women's experiences. BMJ 1993;307: $174-6$. \\ 5 Royal College of Obstetricians and Gynaecologists and Royal College of Paediatrics and Child Health. Fetal abnor- malities: guidelines for screening, diagnosis and management. London: RCOG and RCPCH, 1997.}

\section{Usefulness of contacting other experts when conducting literature searches}

\section{Secondary citation of work that was not published did not set good example}

Editor-McManus et al described the usefulness of hand searching and contacting other experts when conducting a literature search. ${ }^{1}$ The eight authors were all contributors, and one of them acted as guarantor.

As occasional authors of systematic reviews we were particularly interested in the assertion that "electronic databases, such as Medline, may detect only about half of papers identified by the gold standard of hand searching journals." We read the paper cited as the reference for this information. It was another $B M J$ article. ${ }^{2}$ We could not, however, find the original data suggesting that hand searching is a gold standard, or that electronic databases find only half of relevant papers. Reference was made to another work. Whether this was the original source of data is still unclear to us, since the reference was not an to article or even an abstract but to a communication presented at a workshop held in March 1992.

McManus et al's short paper was on medical publication and was published in a leading journal in this field. A major reference regarding the background and the results of the study was the secondary citation of a paper reported at a workshop 
six years before. Papers reported at meetings should be cited only in the text, not as formal references, ${ }^{3}$ and secondary citations should be identified. If a work unpublished several years after oral presentation deserves mention it should be presented unambiguously to readers.

Only a fraction of readers can afford to spend time scrutinising the literature cited and to check the validity of references. Whether this should be done by the editor, the referees, the contributors, or the guarantor can be debated.

Patrick Chariot Senior registrar in legal medicine and toxicology

Vivien Pautot Medical student

Hôpital Henri Mondor, 94010 Créteil, France

1 McManus RJ, Wilson S, Delaney BC, Fitzmaurice DA, Hyde CJ, Tobias RS, et al. Review of the usefulness of contacting other experts when conducting a literature search for systematic reviews. BMJ 1998;317:1562-3.

2 Chalmers I, Dickersin K, Chalmers TC. Getting to grips with Archie Cochrane's agenda. BMJ 1992;305:786-7.

3 Getting published in the BMJ: advice to authors. BMJ Getting publish

\section{Study only "proves" what librarians knew} anyway

EDITOR-I have noticed that scientifically minded people are often unscientific in their approach to fields other than their own. McManus et al, in their short "review" on the usefulness of contacting experts to help identify publications, provide a case in point. $^{1}$ I use the word case advisedly, because their short paper was not a review but a case study. The claim is made that "this study has ... found [experts] to be an essential source for identifying literature." This conclusion may be true, but it is not warranted by the study.

The authors also claim that the study "confirms that searching electronic databases may uncover only half of all relevant

\section{Advice to authors}

We prefer to receive all responses electronically, sent either directly to our website or to the editorial office as email or on a disk. Processing your letter will be delayed unless it arrives in an electronic form.

We are now posting all direct submissions to our website within 72 hours of receipt and our intention is to post all other electronic submissions there as well. All responses will be eligible for publication in the paper journal.

Responses should be under 400 words and relate to articles published in the preceding month. They should include $\leqslant 5$ references, in the Vancouver style, including one to the BMJ article to which they relate. We welcome illustrations.

Please supply each author's current appointment and full address, and a phone or fax number or email address for the corresponding author. We ask authors to declare any competing interest. Please send a stamped addressed envelope if you would like to know whether your letter has been accepted or rejected.

Letters will be edited and may be shortened.

www.bmj.com

letters@bmj.com studies." Strictly speaking, this statement is correct, in the sense that sighting a second, or perhaps a third, black swan confirms that searching for a swan might turn up one that is not white. But really the study confirms nothing of importance: it simply provides an example of what may be an important fact along the lines of "half of all swans (hitherto believed to be white) are in fact black."

The article merely underlines a truismthat experts know about publications in their fields and therefore might usefully be consulted in a search for articles. It goes to great lengths to knock down a straw man-the claim that Medline searches invariably generate comprehensive bibliographies-which nobody who was an expert in my specialty (librarianship) would have erected in the first place.

Stephen Due Chief librarian

Geelong Hospital, PO Box 281, Geelong 3220, Australia

1 McManus RJ, Wilson S, Delaney BC, Fitzmaurice DA, Hyde CJ, Tobias RS, et al. Review of the usefulness of contacting other experts when conducting a literature search for systematic reviews. $B M J$ 1998:317:1562-3.

\section{Authors' reply}

EditoR-We admire Chariot and Pautot's diligence in their scrutiny of our references but feel that they have missed the simple message of our article. For reviews of developing fields such as primary care in general and near patient testing in particular, failure to contact experts in the field is likely to lead to a considerable shortfall in relevant studies being identified. We took care to limit our findings in this way as others have achieved better results from searching databases in more developed fields. ${ }^{1}$

We are not alone in finding shortfalls when identifying articles from primary care on electronic databases. ${ }^{2}$ With regard to the fragility of the referencing, Chariot and Pautot are right to bring attention to the paucity of work in this field but may not appreciate the editorial limitations placed on short reports. ${ }^{3}$ As far as gold standards for the identification of relevant articles are concerned, it is hard to see what could be used other than hand searching all publications. This would not be feasible, given the huge potential range of literature.

Due seems to be arguing from the opposite point of view-that studies confirming truisms should not be published. We disagree with him and argue that it makes better science to demonstrate the self evident rather than accept it at face value. Librarians may be aware of the methodological weaknesses in electronic database searching, but clinicians may not be. Systematic reviews are an important method of distilling research knowledge and are increasingly used to define the agenda for future research. It is important to understand the potential pitfalls in such reviews before acting on them. Perhaps this letter was an attempt at swan-upmanship.

R J McManus Clinical research fellow

S Wilson Senior research fellow

B C Delaney Senior lecturer
D A Fitzmaurice Senior lecturer

R S Tobias Research fellow

S Jowett Research associate

F D R Hobbs Professor

Department of General Practice, University of

Birmingham, Birmingham B15 2TT

r.j.mcmanus@bham.ac.uk

C J Hyde Director

Aggressive Research Intelligence Facility,

Department of Public Health, University of

Birmingham

1 Dickersin K, Scherer R, Lefebvre C. Identifying relevant studies for systematic reviews. BMJ 1994;309:1286-91.

2 Silagy C. Developing a register of randomised controlled trials in primary care BMJ 1993;306:897-900.

3 Getting published in the BMJ: advice to authors. BMJ 1997;314:66-8.

\section{Clocks in delivery wards may not be sufficiently accurate to validate birth of "millennium babies"}

EDitoR-There has been much interest recently in "millennium babies" and the many couples who are attempting to have the first baby born in the new millennium. Validation of the "first baby" requires an accurate clock in the labour room, but this may not always be the case.

In our labour ward, where 2600 babies a year are delivered, each room has an independent battery-powered quartz clock. We compared the time given by these clocks against the BT speaking clock. All six clocks in the delivery rooms were slow, by a median of 93.6 seconds (range 2 minutes 28 seconds to 47 seconds). The clock at the central nursing station was 4 minutes 10 seconds slow, and, by comparison, the central clock in the special care baby unit was 24 seconds slow.

This is not just a problem in the smaller peripheral units. We also surveyed a labour ward in a large teaching hospital, with independent battery-powered clocks. The median of the 11 clocks was 15 seconds slow, but they ranged from 4 minutes 12 seconds slow to 2 minutes 25 seconds fast. The main clock in the neonatal intensive care unit was 55 seconds fast.

Most parents expect the clocks to be accurate and might be surprised if their babies became 5 minutes older during transfer to a neonatal intensive care unit from the labour ward. The midwives thought that the early shift might prefer a slow central clock.

Jonathan Round Specialist registrar in paediatrics 12 Hansler Road, East Dulwich, London SE22 9DJ jround9@yahoo.com

Nigel Kennea Specialist registrar in paediatrics (neonatology)

Department of Child Health, St George's Hospital Medical School, London SW17 0RE

n.ykennea@btinternet.com

Rapid responses
$\begin{aligned} & \text { Correspondence submitted electronically } \\ & \text { is available on our website www.bmj.com }\end{aligned}$

